\title{
Perbaikan Manajemen Internal KWT Amanah Bausasran Menuju Kelompok Tani Yang Berkemajuan
}

\author{
Isthofaina Astuty ${ }^{1}$, Meika Kurni PRDA ${ }^{2}$ \\ 1,2 Program Studi Manajemen, Fakultas Ekonomi dan Bisnis, Universtitas Muhammadiyah Yogyakarta \\ Email: isthofainaastuty@umy.ac.id \\ DOI: $10.18196 / p p m .34 .302$
}

\begin{abstract}
Abstrak
Kelompok Tani KWT Amanah yang berlokasi di Masjid Al Amna Bausasran sudah berdiri sejak 21 Januari 2012, namun sejak tahun 2017 perkembangan tidak mengembirakan bahkan bisa dikatakan mengalami penurunan. Hasil observasi di lapangan dan ditindaklanjuti dengan wawancara dengan berbagai pihak menunjukkan beberapa permasalah mitra yang membuat kondisi KWT Amanah saat ini kurang mengembirakan dan terkesan kurang mendapatkan perhatian dari anggota dan pengurus KWT Amanah. Permasalahan yang terindentifikasi adalah kurang bagusnya komunikasi dan koordinasi dalam internal KWT Amanah, manajemen pengelolaan organisasi yang kurang berkualitas, program kegiatan yang kurang variatif serta kurangnya variasi tanaman. Agar komunikasi dan kordinasi berjalan dengan baik, maka solusi yang ditawarkan adalah berbagai kegiatan pendampingan yang mampu meningkatkan konsolidasi antar anggota KWT Amanah serta dilakukan penyegaran kembali tentang manajemen pengelolaa kelompok tani. Solusi yang dipilih terkait dengan masalah produksi adalah penyelengaraan lomba menanam sayur pada anggota KWT. Terkait dengan kurangnya variasi tanaman, maka solusi yang ditawarkan adalah pengadaan tanaman sayur. Melalui metode pendampingan dan didukung dengan pengadaan kegiatan dan fasilitas kebun, maka luaran yang diharapkan dari program pengabdian masyarakat, yakni KWT Amanah yang dikelola dengan manajemen yang baik serta mampu memberikan kontribusi sosial ekonomi kepada para anggota di lingkungan PRA Bausasran
\end{abstract}

Kata kunci: kelompok tani, manajemen , tanaman

\section{Pendahuluan}

Ketika pemerintah kota Yogyakarta menyerukan pemanfaatan lahan sempit dengan penanaman sayur, buah dan tanaman obat pada tahun 2019, kelompok Tani KWT Amanah yang berlokasi di Kedai Amanah Masjid Al Amna Bausasran dan beralamatkan di Bausaran DN III/389 Yogyakarta sudah melakukan penanaman sayur dan tanaman obat sejak tahun 2012. KWT atau Kelompok Wanita Tani adalah kelompok tani yang anggotanya adalah para wanita yang melaksanakan usahanya di bidang pertanian, para istri petani dan anggota kelompok tani (Nuryono, 2019). Banyak dukungan yang telah diterima oleh kelompok tani ini seperti dukungan dari takmir Masjid Al Amna yang berupa dukungan moril dan materiil kepada KWT Amanah dari tahun 2000 hingga sekarang, serta dukungan dari pemerintah dan lembaga-lembaga terkait dalam bentuk berbagai pelatihan, perlengkapan dan material perkebunan dikarenakan KWT Amanah termasuk pelopor kelompok tani di Kalurahan Bausasran. Namun banyaknya dukungan yang didapat tidak sebanding dengan perkembangan KWT AMANAH. Pada awal pendirian sampai tahun 2017, perkembangan kelompok tani wanita ini mengalami pasang surut, bahkan pernah mengalami mati suri. Sepanjang tahun 2012 - 2017, KWT AMANAH pernah memiliki banyak program pelatihan baik yang terkait dengan perkebunan maupun tentang pengolahan hasil kebun dan perikanan, memiliki kebun yang dikelola dengan baik dan kolam pembesaran lele serta bergerak dalam pengemasan produk olahan. Namun sayang hanya kebun saja yang bertahan dan itupun hanya ditangani oleh beberapa orang anggota yang bertahan. Kondisi itu sejalan dengan hasil penelitian yang dilakukan oleh mahasiswa Agribisnis UMY, dengan judul Partisipasi Anggota Kelompok Tani Dalam Kegiatan Optimalisasi Pemanfaatan Lahan Pekarangan Perkotaan Pada Gapoktan Bausasran Di Kelurahan Bausasran Kecamatan Danurejan Kota Yogyakarta,2017 yang menyatakan bahwa beberapa kelompok tani yang berdomisili di Bausasran salah satunya KWT Amanah hanya aktif dalam menjalankan beberapa fungsi dari kelompok tani (Putri Ayu Masruroh,2017) Pada tahun 2018 sampai 
dengan tahun 2019 pengurus KWT AMANAH didukung oleh pimpinan PRA Bausasran berusaha untuk menghidupkan kembali kelompok ini namun hasilnya belum menggembirakan.

Hasil observasi di lapangan yang dilakukan dengan pengamatan langsung ke lokasi KWT Amanah beberapa kali, diskusi secara personal dengan anggota dan pengurus KWT Amanah dan pengurus PRA Aisyiyah, serta tanya jawab dengan takmir Masjid Al Amna menunjukkan beberapa permasalah mitra yang membuat kondisi KWT Amanah saat ini kurang mengembirakan dan terkesan kurang mendapatkan perhatian dari anggota dan pengurus KWT Amanah sehingga KWT Amanah agak jauh tertinggal dengan kondisi Kelompok Tani lainnya, bahkan yang jauh lebih muda. Permasalahan-permasalah yang terindentifikasi dapat dikelompokkan menjadi aspek manajemen dan aspek produksi. Dalam aspek manajemen permasalahan yang muncul adalah : 1) kurang baiknya komunikasi dan koordinasi dalam internal KWT AMANAH, baik antar pengurus maupun pengurus dengan anggota sehingga sering muncul konflik berkepanjangan yang mengurangi semangat untuk melakukan kegiatan; 2) kurangnya kegiatan yang ditujukan untuk meningkatkan konsolidasi antara pengurus dan anggota KWT Amanah. Akhir-akhir ini kegiatan hanya fokus pada bagaimana kebun KWT Amanah bisa tetap eksis sehingga melupakan kegiatan yang bertujuan untuk meningkatkan kekompakan dan konsilidasi anggota; 3) menurunnya tingkat semangat pengurus dan anggota untuk mengelola KWT Amanah dengan sebaikbaiknya dikarenakan perasaan bosan yang cenderung tinggi dan konflik personal yang muncul di permukaan; 4) manajemen pengelolaan KWT Amanah yang perlu di-segar-kan kembali agar administrasi KWT Amanah kembali berjalan dengan baik. Dalam aspek produksi, permasalahan yang teridentifikasi adalah: 1) KWT Amanah hanya memiliki satu kebun dan itu letaknya di Masjid Al Amna. Hal ini sedikit banyak mengurangi "rasa memiliki" anggota KWT Amanah pada kebun Amanah sendiri, 2) Kurangnya variasi tanaman di KWT Amanah, padahal area kerja KWT Amanah masih sangat luas; 3) KWT AMANAH belum memiliki keunikan yang menjadi pembeda dari kelompok tani lain. Oleh karena itu pengabdian kali ini lebih ditujukan pada menawarkan berbagai alternatif pemecahan masalah yang dihadapi KWT AMANAH berdasarkan pada kajian akademik terhadap persoalan yang dihadapi kelompok wantita tani, baik secara langsung maupun tidak langsung (Direktorat Riset dan Pengabdian Masyarakat, 2018). Dari berbagai masalah mitra yang teridentifikasi, solusi yang ditawarkan adalah sebagai berikut:

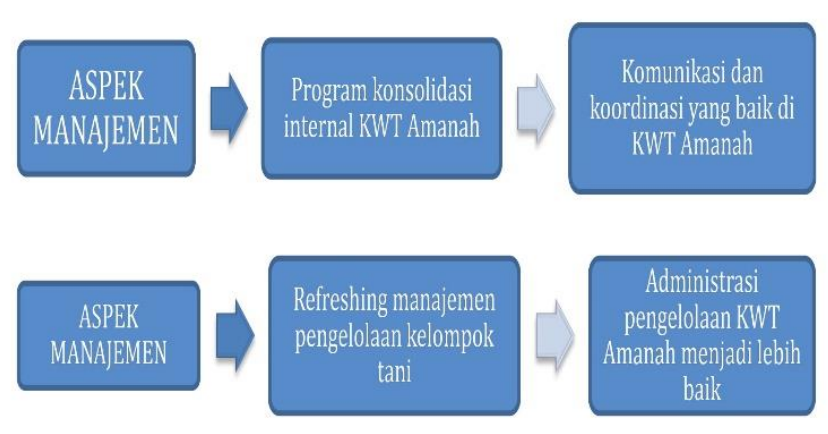

Gambar 1. Solusi dan Target Bidang Garap Aspek Manajemen 


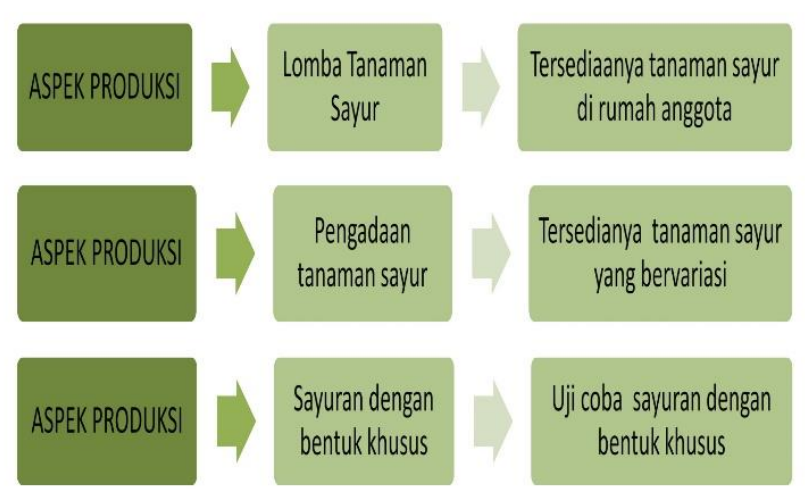

\section{Gambar 2: Solusi dan Target Aspek Produksi}

Hasil dari diskusi dengan berbagai kalangan yang memiliki kontribusi pada perkembangan KWT Amanah, masalah manajemen harus terlebih dahulu dicarikan solusinya kerena masalah manajemen berhubungan dengan sumberdaya insani penggerak utama KWT Amanah. Agar komunikasi dan kordinasi berjalan dengan baik, maka solusi yang ditawarkan adalah berbagai kegiatan yang mampu meningkatkan konsolidasi antar anggota KWT Amanah serta dilakukan penyegaran kembali tentang manajemen pengelolaan kelompok tani.

Solusi yang dipilih terkait dengan masalah produksi adalah penyelenggaraan lomba tanaman sayur bagi anggota KWT Amanah. Terkait dengan kurangnya variasi tanaman , maka solusi yang ditawarkan adalah pengadaan berbagai tanaman sayur yang sesuai dengan kondisi lahan KWT Amanah. Solusi terakhir dalam aspek produksi adalah diadakan uji coba membentuk tanaman sayur dengan bentuk khusus

\section{Metode Pelaksanaan}

Untuk menjamin bahwa program pengabdian masyarakat yang merupakan salah satu pembentuk program pemberdayaan masyarakat (community empowerment) mengikuti prinsip-prinsip kesetaraan, kemandirian, partisipasi dan berkelanjutan (Sri Najiati, Agus Asmana, I Nyoman N Suryodiputro, 2005), maka metode pelaksanaan yang dirancang dalam pengabdian masyarakat di KWT Amanah adalah:

1. Observasi

Metode pelaksanaan observasi digunakan di awal pengajuan proposal untuk mendapatkan gambaran umum permasalahan di target pengabdian masyarakat. Namun metode ini juga digunakan di awal proses persiapan dalam rangka pelaksanaan program pengabdian masyarakat untuk mendapatkan gambar detail dari permasalahan KWT Amanah serta sebagai dasar penentuan teknik pelaksanaan program-program yang direncanakan agar berjalan sesaui dengan usulan dan berjalan lancar.

2. Diskusi

Untuk mendapatkan gambaran secara detail permasalahan di KWT Amanah, tim pengabdian masyarakat perlu melakukan beberapa kali diskusi dengan berbagai pihak terkait, seperti dengan pengurus KWT Amanah, dengan anggota, pengurus PRA Bausasran serta takmir masjid Al Amanah selaku pemilik lahan di mana KWT Amanah melakukan aktivitas selama ini.

3. Pendampingan

Dalam proses pelaksanaan pengabdiaan masyarakat ini, moyoritas program harus dilakukan dengan metode pendampingan dikarenakan akar permasalahan di KWT AMANAH adalah rendahnya kualitas koordinasi dan komunikasi di internal kelompok ini sehingga berdampak munculnya permasalahan yang lain.

4. Pengadaan 
Dalam upaya memperlancar jalannya program pengabdian di KWT Amanah, serta memfasilitasi beberapa program, maka perlu dilakukan pengadaan beberapa perlengkapan perkebunan, bibit tanamam serta media tanam juga alat tulis yang dibutuhkan dalam proses pelaksanaan pengabdian masyarakat.

\section{Hasil dan Pembahasan}

\section{Persiapan Pelaksanaan Program}

Agar program pendampingan KWT Amanah PRA Bausasran menuju KWT yang mandiri ini dapat dilaksanakan dengan lancar, maka sebelum semua kegiatan dimulai, terlebih dahulu dilakukan silarurahmi dan diskusi terhadap pihak terkait, yakni dengan pengurus dan anggota senior KWT Amanah, pengurus Pimpinan Ranting Aisyiyah Bausasran (PRA Bausasran), para penyuluh pertanian di wilayah Bausasran. Adanya diskusi awal ini diharapkan semua pihak terkait akan mendukung sepenuhnya program ini baik secara kelembagaan, materiil maupun moril.

2. Tahapan Pelaksanaan

Adapun tahap pelaksanaan PKM ini adalah sebagai berikut:

a. Bidang Garap I Aspek Manajemen

i. Peningkatan konsolidasi anggota KWT AMANAH dengan melakukan berbagai macam kegiatan seperti penyelanggaraan pertemuan anggota secara rutin dan menggiatkan kembali kerja bakti semua anggota setiap pekan sekali.

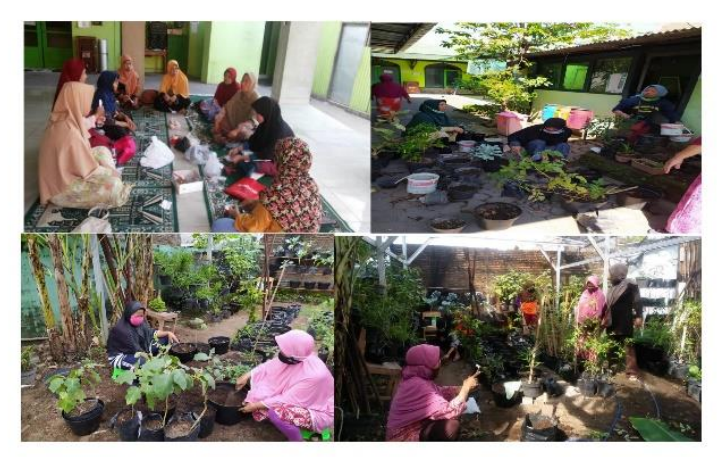

Gambar 3 : Rapat Pengurus dan Kerja bakti

ii. Penyegaran manajemen organisasi, khususnya pengelolaan kelompok tani. Manajemen yang diartikan sebagai seni mengelolaan sumberdaya organisasi untuk mencapai tujuan organisasi (Coulter, 2016) harus menjadi dasar setiap organisasi untuk menjalankan fungsi dengan baik. Begitu juga dengan kelompok tani, ketika kelompok tani mengurangi kualitas manajemen organisasi maka banyak kerugian yang akan muncul. Oleh karena itu begitu dirasa ada miss management dalam pengelolaan kelompok tani harus segera dilakukan penyegaran kembali agar peran dan fungsi kelompok tani bisa kembali normal. Satu kegiatan yang dirasa diperlukan untuk mengembalikan fungsi-fungsi pengurus adalah melakukan Rapat Anggota yang selama ini belum pernah dilakukan. Dalam rapat ini dilakukan pemilihan kembali pengurus KWT Amanah dan program kerja. Dalam program ini tim pengabadian masyarakat juga memperbaiki kualitas administrasi, baik administrasi kegiatan maupun administrasi keuangan (Andi Magfiranur, 2019). 


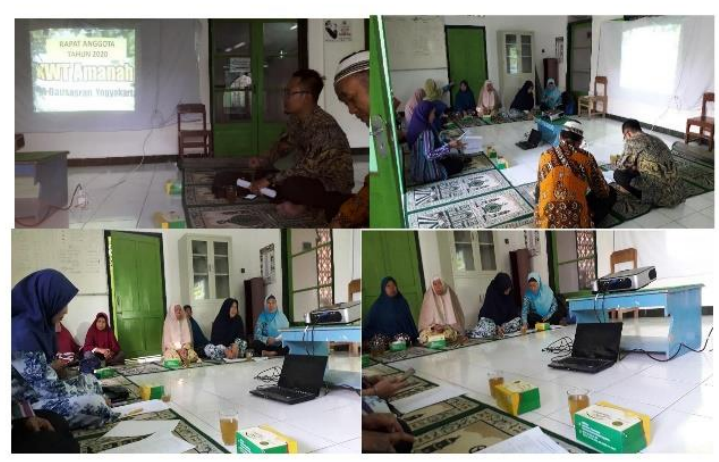

Gambar 4 : RAPAT ANGOTA KWTAMANAH TH 2020

\section{b. Bidang Garap II Aspek Produksi}

i. Pengadaan lomba penanaman sayur pada anggota KWT AMANAH. Dilakukan pada bulan Februari 2020 sd Mei 2020. Masing-masing anggota mendapatkan 6 pohon usia 1 bulanan terdiri bibit pohon Cabe, Terong dan Tomat untuk dirawat di rumah masing-masing. Pada bulan Mei dilakukan penjurian yang dilakukan di area lahan KWT AMANAH dengan juri Petugas Penyuluh Lapangan serta praktisi.

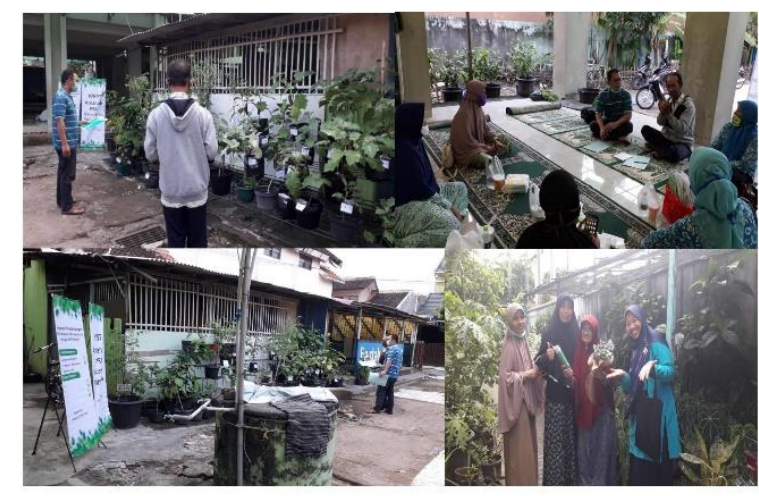

Gambar 5: Penjurian Lomba oleh PPL dan Praktisi, serta Pemenang

ii. Pengadaan variasi tanaman sayur di KWT Amanah. Kegiatan dilakukan dengan pengadaan bibit sayuran, pot yang sesuai dengan potensi besarnya pohon serta media tanam. Secara bersama-sama anggota KWT Amanah melakukan penanaman dan, peletakan tanaman ditempat yang cukup sinar matahari namun aman mengingat area yang dipakai adalah parkir Masjid Al Amanah dan secara bergiliran melakukan perawatan.

iii. Uji coba membentuk buah terong dengan bentuk hati. tersedianya pohon terong yang sudah dewasa dan siap berbuah, menjadikan buah terong sebagai pilihan untuk dibentuk. Langkah selanjutnya adalah pengadaan alat yang dipesan dari Cina dan proses pemasangan alat pada buah-buah Terong yang sudah dipilih. 


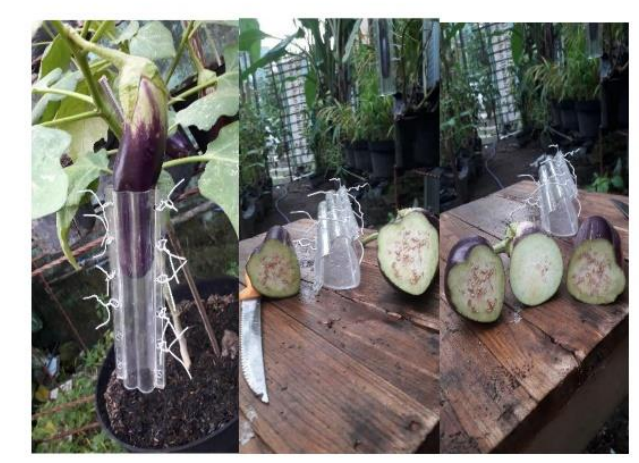

Gambar 6. Uji Coba Buah Terong Berbentuk Hati

\section{Kesimpulan}

Dari pelaksanaan pengabdian masyarakat dengan mitra kerja KWT Amanah, Bausasran Kecamatan Danurejan yang sudah dilakukan sejak bulan Januari sampai dengan bulan Juni 2020 dapat diambil beberapa kesimpulan:

1. Program kegiatan di bidang manajemen yang berupa perbaikan kualitas komunikasi dan koordinasi melalui intensifikasi rapat dan pertemuan rutin adalah program yang sangat dibutuhkan dalam rangka memperbaiki kondisi internal KWT Amanah saat ini.

2. Perbaikan manajemen KWT Amanah yang diawali dengan Rapat Anggota untuk menegaskan posisi kepengurusan dan program kerja dan dilanjutkan dengan perbaikan administrasi adalah langkah penting guna kejelasan struktur dan tindakan kelompok.

3. Penyelenggaraan program yang langsung melibatkan anggota dalam jangka panjang, seperti lomba menanam sayur adalah contoh program yang efektif untuk meningkatkan keterlibatan anggota

4. Pengadaan bibit sayur dalam variasi dan jumlah adalah tindakan yang harus selalu dilakukan guna menjamin ketersedian tanaman sayur di KWT Amanah.

5. Uji coba pembentukan sayur dengan bentuk unik adalah langkah alternatif yang perlu dilanjutkan untuk mendapatkan keunikan dari KWT Amanah.

\section{Ucapan Terima Kasih}

Pelaksanaan pengabdian masyarakat dengan mitra KWT Amanah Bausasran yang dilakukan pada tahun 2020 telah selesai dilakukan dan berjalan lancar sesuai dengan usualan tim. Banyak pihak telah memberikan dukungan dan partisipasi aktif dalam pelaksanaan program ini. Untuk itu kami selaku tim pengabdian masyarakat mengusapkan terimaka kasih, khususnya kepada:

1. LP3M UMY selaku pemberi dana dengan no kontrak 031/PEN-LP3M/I/2020

2. Ketua dan pengurus KWT Amanah Bausasran

3. Anggota KWT Amanah Bausasran

4. Pimpinan Ranting Bausasran

5. PPL wilayah Danurejan

\section{Daftar Pustaka}

Andi Magfiranur, 2019,Kelengkapan Administrasi Kelompok Tani Wanita, http://cybex.pertanian.go.id

Coulter, R. (2016). Manajemen Jilid 1 Edisi ke 16. Jakarta: Penerbit Salemba.Direktorat Riset dan Pengabdian Masyarakat,2018, Panduan Penelitian dan Pengabdian Kepada Masyarakat ,edisi xii 


\section{6}

Nuryono, 2019,Peran Kelompok Wanita Tani (KWT) Mendukung Pelaksanaan Materi Penyuluhan Pertanian, http://cybex.pertanian.go.id

Putri Ayu Masruroh,2017, Partisipasi Anggota Kelompok Tani Dalam Kegiatan Optimalisasi Pemanfaatan Lahan Pekarangan Perkotaan Pada Gapoktan Bausasran Di Kelurahan Bausasran Kecamatan Danurejan Kota Yogyakarta,Skripsi UMY, Yogyakarta

Sri Najiati, Agus Asmana, I Nyoman N Suryodiputro, 2005, Pemberdayaan Masyarakat di Lahan Gambut 